\title{
ESTIMATING THE EXTREME SINGULAR VALUES OF MATRICES
}

\author{
CHI-KwONG $\mathrm{LI}^{\dagger}$ AND CARrie A. POHANKA
}

Abstract. Algorithms are derived to obtain upper and lower bounds for the largest and smallest singular values of a square complex matrix in terms of its eigenvalues and Frobenius norm. These bounds are best possible in the sense that they are attainable by some matrices with the prescribed eigenvalues and Frobenius norm. Numerical examples are given to compare them with those in the literature.

Mathematics subject classification (1991): 15A42.

Key words and phrases: Singular value, eigenvalue, Frobenius norm.

\section{REFERENCES}

[G] M. I. GIL', Norm Estimations for Operator-Valued Functions and Applications, Marcel Dekker, New York, 1995.

[HJ $\quad$ R. A. HoRn AND C. R. Johnson, Topics in Matrix Analysis, Cambridge University Press, Cambridge, 1991.

[MO] A. W. Marshall AND I. OlKIn, Inequalities: Theory of Majorization and Its Applications, Academic Press, New York, 1979.

[Me] J. K. MERIKOSKI ET AL., A best upper bound for the 2-norm condition number of a matrix, Linear Algebra Appl. 254 (1997), 355-366.

[S] G. W. STEWART, On the early history of the singular value decomposition, SIAM Rev. 35 (1993), $551-566$. 